\title{
Cleft palate-lateral synechia syndrome: first reported case in Sri Lanka
}

\author{
Malithi Guruge', *Manori Gamage ${ }^{2}$, Ruwanthi Perera², Saraji Wijesekera ${ }^{2}$, Suthesan Kandasamy ${ }^{1}$ \\ Sri Lanka Journal of Child Health, 2021; 50(2): 359-361 \\ DOI: http://dx.doi.org/10.4038/sljch.v50i2.9592 \\ (Key words: Cleft palate, intra oral fibrous bands, CPLS syndrome)
}

\section{Introduction}

Cleft lip and palate are the commonest craniofacial abnormalities reported in humans ${ }^{1}$ but intraoral epithelial bands or synechiae are rare. Presence of lateral synechia and cleft palate together is very rare and is known as cleft palate-lateral synechia (CPLS) syndrome ${ }^{2}$. In addition to the above, intraoral synechiae are known to be associated with some other syndromes, namely, van der Woude syndrome, and popliteal pterygium syndrome 3 . Here we present the first reported case of a neonate with CPLS in Sri Lanka.

\section{Case report}

A baby boy was born to a non-consanguineous couple at term as their first child. Mother was 25 years old, a known patient with type 2 diabetes mellitus and chronic hypertension. She also had a past history of isolated cleft palate which was repaired during her childhood. Father was a 25 year old healthy, product manager in a private company. At birth, the baby was found to have micrognathia and bilateral intraoral fibrous bands connecting mandible to maxilla. These bands compromised the opening of the mouth and affected feeding of the baby significantly. Further examination revealed a posterior cleft palate. No lip pits were noted. Other systems examination was unremarkable. Baby was further screened for other associated congenital anomalies with an echocardiogram and ultrasonogram of brain and abdomen. All were found to be normal.

Baby was further evaluated by an ear nose and throat (ENT) surgeon and a plastic surgeon on the

${ }^{1}$ Colombo South Teaching Hospital, Kalubowila, Sri Lanka, ${ }^{2}$ University of Sri Jayewardenepura, Sri Lanka

*Correspondence: manorigamage@sjp.ac.lk

(iD https://orcid.org/0000-0003-3836-5945

(Keceived on 05 December 2019: Accepted after revision on 24 January 2010)

The authors declare that there are no conflicts of interest

Personal funding was used for the project.

Open Access Article published under the Creative

Commons Attribution CC-BY (c) (i) License second day of life and it was decided to remove the fibrous bands to support his feeding. He was commenced on expressed breast milk using a bottle with a special teat, till excision of fibrous bands. In the operating theatre, he was examined further and was found to have $3 \mathrm{~mm}$ (Figure 1) and $1 \mathrm{~mm}$ long thick fibrous bands connecting the palate to alveoli on the right side and two $1 \mathrm{~mm}$ long thick fibrous bands on the left side (Figure 1). Further, a tonguetie was visualized. All four fibrous bands were removed and the tongue-tie was released by electro cauterization under gas-induced sedation without any peri- or post-operative complications. He was commenced on enteral feeds post operatively using the same special feeding bottle recommended for the cleft palate. He is thriving and awaiting surgical correction of his cleft palate.

\section{Discussion}

Adhesions between anatomic structures are known as synechiae. Oral synechiae are fibrous bands which occur between upper and lower alveolar ridges (syngnathism/ alveolar synechia) or between tongue and margins of the palate or maxilla (glosso-palatal ankylosis) ${ }^{4}$.

In 1972, a new syndrome which was a combination of cleft palate, lateral synechiae between palate and floor of the mouth, micrognathia and short upper lip was described by Fuhrmann et al and named CPLS syndrome ${ }^{2}$. This is a very rare condition without a clear aetiology. However, there are reported case series suggestive of autosomal dominant inheritance with variable penetrance ${ }^{5}$. Oral synechiae occur at various locations and are classified according to the extent of the two connecting surfaces ${ }^{1}$.

Exact aetiology of CPLS is not clear ${ }^{6}$ but two main aetiological theories are described. According to one theory, it occurs due to the persistence of the bucco-pharyngeal membrane ${ }^{7}$. According to the other, an insult occurs during the development of embryo while there is close contact of alveolar ridges, tongue and palatal shelves leading to abnormal fusion ${ }^{8}$.

These synechiae are known to cause feeding and breathing issues due to inability to open their mouth fully and cleft palate ${ }^{1}$. Management is aimed at surgical excision of the fibrous bands and palatal 
closure $^{1}$. During surgical management, the most difficult issue is the maintenance of airway during the surgical procedure. Routine intubation is not possible due to inability to open the mouth and naso-tracheal intubation is difficult in neonates ${ }^{1}$. In cases who need immediate excision, it is done under sedation with extensive and continuous monitoring as in our case ${ }^{1}$.

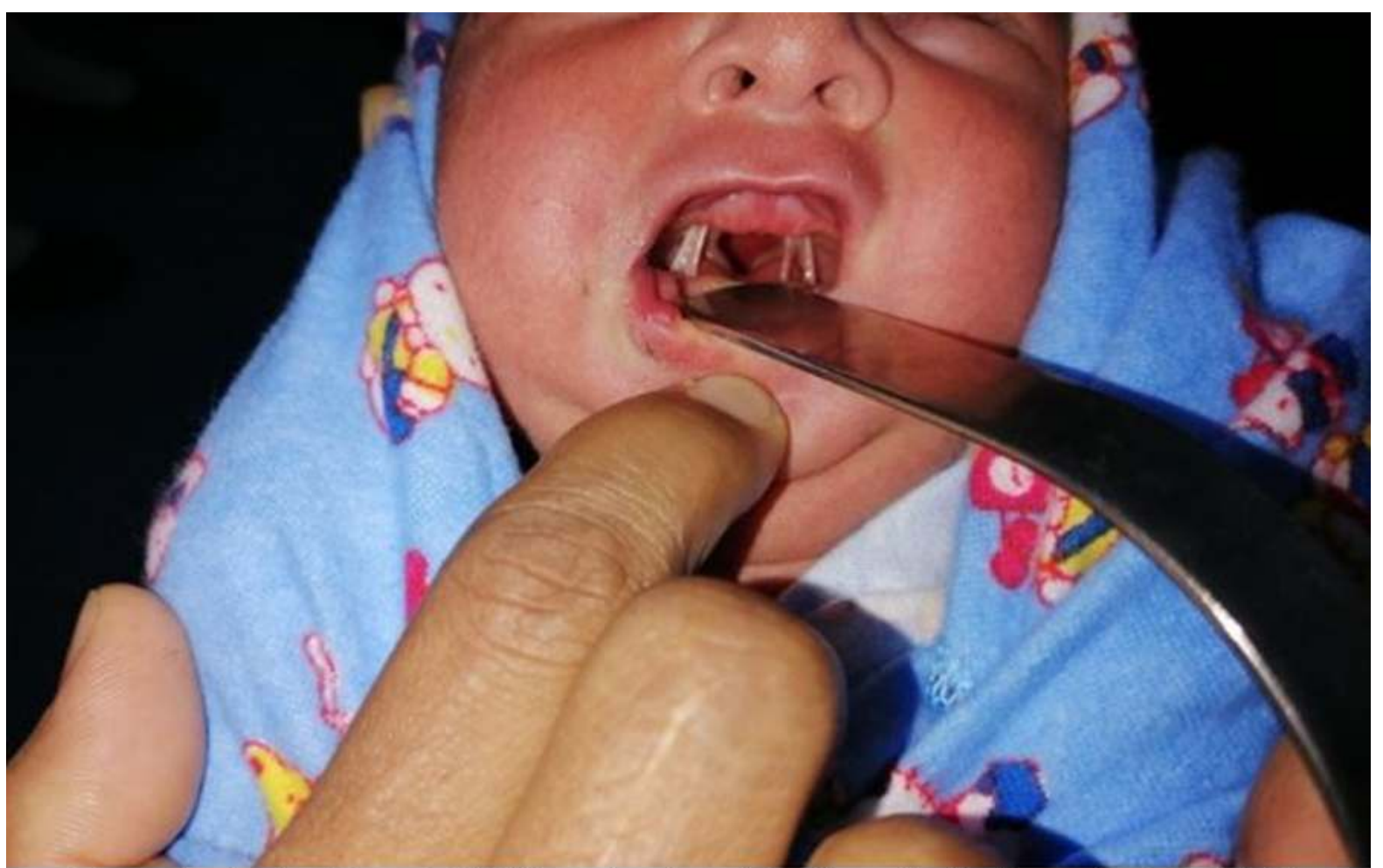

Figure 1: showing 2 lateral thick fibrous bands on right side and 2 thin fibrous bands on left side

\section{Reference}

1. Sybil D, Sagtani A. Cleft palate lateral synechia syndrome. National Journal of Maxillofacial Surgery 2013; 4:87-9. https://doi.org/10.4103/0975-5950.117876 PMid: 24163560 PMCid: PMC3800393

2. Fuhrmann W, Koch F, Schweckendiek W. Autosomal dominant inheritance of cleft palate and synechiae between the palate and floor of the mouth or tongue. Humangenetik 1974; 14:196-203. https://doi.org/10.1007/BF00278039 PMid: 5052209

3. Fakhim SA, Bayazian G, Notash R. Case Report -Cleft palate lateral synechia syndrome: hereditary or not? Egyptian Journal of Ear, Nose, Throat and Allied Sciences 2014; 15: 173-5. https://doi.org/10.1016/j.ejenta.2014.02.00 3
4. Dindaro NM, Christian JM, Bennett JA, Shutack JG. Cleft palate lateral synechia syndrome. Review of the literature and case report. Oral Surgery, Oral Medicine, and Oral Pathology 1989; 68(5): 565-6 https://doi.org/10.1016/00304220(89)90240-5

5. Donepudi SK, Stocks RMS, Pivnick EK, Mineck C, Thompson JW. Cleft palate lateral synechia syndrome: An opportunity for unique surgical closure. International Journal of Pediatric Otorhinolaryngology 2009; 73(6), 861-6.

https://doi.org/10.1016/j.ijporl.2009.03.00 8

PMid: 19368978

6. Gharavifard M, Kashani I, Joudi M, Sharifian M, Sayedi SJ, Mohammadipanah B, et al. Surgery and anaesthesia management for intraoral synechia: A case report. Iranian Journal of Otorhinolaryngology 2018; 30(97): 117-9. 
7. Longacre JJ. Congenital atresia of the oropharynx. Plastic and Reconstructive Surgery 1946; 8:341-8.

https://doi.org/10.1097/00006534-

195111000-00002

PMid: 14891381
8. Haydar SG, Tercan A, Uçkan S, Gürakan

B. Congenital gum synechiae as an isolated anomaly: A case report. Journal of Clinical Pediatric Dentistry 2003; 28:81-3.

https://doi.org/10.17796/jcpd.28.1.j34125 00v2375v06

PMid: 14604148 